\section{Human, Social, and Environmental Impacts of Human Genetic Engineering}

\section{Abstract}

Genetic engineering can simply be explained as the alteration of an organism's genetic, or hereditary, material to eliminate undesirable characteristics or to produce desirable new ones.

Several works have been done on genetic engineering with major focus on its importance ranging from increasing plant and animal food production, diagnosing disease condition, medical treatment improvement, as well as production of vaccines and other useful drugs. Methods in this techniques involve the selective breeding of animals and plants, hybridization (reproduction between different strains or species), and recombinant deoxyribonucleic acid (rDNA).

Keywords: Genetic Engineering; Ethical and Social Implication

\section{Satyajit Patra and Araromi Adewale Andrew}

American International Medical University, Bosejour Road, Gros Islet, Saint Lucia

\section{Corresponding author: Satyajit Patra}

American International Medical University, Bosejour Road, Gros Islet, Saint Lucia.

\section{dr.patra@aimu-edu.us}

Citation: Patra S, Andrew AA. Human, Social, and Environmental Impacts of Human Genetic Engineering. J Biomedical Sci. 2016, 4:2.

\section{Introduction}

Human genetic engineering relies heavily on science and technology. It was developed to help end the spread of diseases. With the advent of genetic engineering, scientists can now change the way genomes are constructed to terminate certain diseases that occur as a result of genetic mutation [1]. Today genetic engineering is used in fighting problems such as cystic fibrosis, diabetes, and several other diseases. Another deadly disease now being treated with genetic engineering is the "bubble boy" disease (Severe Combined Immunodeficiency). This is a clear indication that genetic engineering has the potential to improve the quality of life and allow for longer life span [2].

Clearly, one of the greatest benefits of this field is the prospect of helping cure illness and diseases in unborn children. Having a genetic screening with a fetus can allow for treatment of the unborn. Overtime this can impact the growing spread of diseases in future generations.

However, these benefits are not without peril. Human genetic engineering is a development that people are either very passionate about or opposed to completely. This article gives a brief account on the effect of this principle on the biosphere together with several controversial issues that accompany the acceptance of this technology [3]. The manuscript has been prepared by using information from peer reviewed journals indexed in pubmed in the period of 2000 to 2015.

\section{Effects on the Environment}

Although the positive impacts of this field could be enormous, there are many questions raised that needs to be answered. New organisms created by genetic engineering could present an ecological problem. One cannot predict the changes that a genetically engineered species would make on the environment. The release of a new genetically engineered species would also have the possibility of causing an imbalance in the ecology of a region just exotic species would do. An accident or an unknown result could cause several problems. An accident in engineering the genetics of a virus or bacteria for example could result in a stronger type, which could cause a serious epidemic when released. This could be fatal in human genetic engineering creating problems ranging from minor medical problems, to death [4].

\section{Effects on Human}

Looking at the fact that genetic engineering employs viral vector that carries functional gene inside the human body; the repercussion are still unknown. There are no clues as to where functional genes are being placed. They may even replace the important genes, instead of mutated genes. Thus, this may lead to another health condition or disease to human. Also, as defective genes are replaced with functional gene, then it is expected that there will be a reduction in genetic diversity and if human beings will have identical genomes, the population as a whole will be susceptible to virus or any form of diseases [5]. 
Genetic engineering could also create unknown side effects or outcomes. Certain changes in a plant or animal could cause unpredicted allergic reactions in some people which, in its original form, did not occur. Other changes could result into the toxicity of an organism to humans or other organisms.

\section{Antibiotic Resistance}

Genetic engineering often uses genes for antibiotic resistance as "selectable markers." Early in the engineering process, these markers help identify cells that have taken up foreign genes. Although they have no further use, the genes continue to be expressed in plant tissues. Most genetically engineered plant foods carry fully functioning antibiotic-resistance genes.

The presence of antibiotic-resistance genes in foods could have lethal effects. Therefore, eating these foods could reduce the effectiveness of antibiotics to fight disease when these antibiotics are taken with meals. More so, the resistance genes could be transferred to human or animal pathogens, making them impervious to antibiotics. If transfer were to occur, it could aggravate the already serious health problem of antibioticresistant disease organisms [6].

\section{Ethical and Social Issues}

"Playing God" has become a strong argument against genetic engineering. Several issues have also been raised as regards the acceptance of this technology. These concerns range from ethical issues to lack of knowledge on the effects genetic engineering may have. One major concern is that once an altered gene is placed in an organism, the process cannot be reversed.

Public reaction to the use of rDNA in genetic engineering has been mixed. The production of medicines through the use of genetically altered organisms has generally been welcomed. However, critics of rDNA fear that disease-producing, organisms used in some rDNA experiments might develop extremely infectious forms that could cause worldwide epidemics [7].

As more human genes are being used in non-human organisms to create new forms of life that are genetically partly human, new ethical questions arise. For instance, what percentage of human genes does an organism have to contain before it is considered human and how many human genes would a green pepper for example have to contain before it can be eaten without qualms. Human genes are now being inserted into tomatoes and peppers to make them grow faster [8]. This suggests that one can now be a vegetarian and a cannibal at the same time. For meateaters, the same question could be posed about eating pork with human genes. What about the mice that have been genetically engineered to produce human sperm [9]. The question is 'what psychological effect would it pose on the offspring?
Critics have questioned the safety of genetically engineered bovine somatotropin (BST) to increase the milk yield of dairy cows (BST) for both the cows that are injected with it and the humans who drink the resulting milk; owing to the fact that it increases a cow's likelihood of developing mastitis, or infection of the udder, and it also makes cows more susceptible to infertility and lameness [6].

Transgenic plants also present controversial issues. Allergens can be transferred from one food crop to another through genetic engineering. Another concern is that pregnant women eating genetically modified products may endanger their offspring by harming normal fetal development and altering gene expression [10].

In 2002 the National Academy of Sciences released a report calling for a legal ban on human cloning [11]. The report concluded that the high rate of health problems in cloned animals suggests that such an effort in humans would be highly dangerous for the mother and developing embryo and is likely to fail. Beyond safety, the possibility of cloning humans also raises a variety of social issues like the psychological issues that would result for a cloned child who is the identical twin of his or her parent.

Another frightening scenario is the destructive use of genetic engineering. Terrorist groups or armies could develop more powerful biological weaponry. These weapons could be resistant to medicines, or even targeted at people who carry certain genes. Genetically engineered organisms used for biological weapons might also reproduce faster, which would create larger quantities in shorter periods of time, increasing the level of devastation [12].

\section{Conclusion}

Despite all of these current concerns, the potential for genetic engineering is tremendous. However, further testing and research will be required to educate society on the pros and cons of genetic engineering. There is no doubt that this technology will continue to present intriguing and difficult challenges for 21st century scientists and ethicists, and education and meaningful, respectful discourse are just the starting point of what is required to tackle such complex ethical issues. With the newfound breakthroughs in cloning, the capabilities of changing human characteristics are unpredictable. We can then anticipate intense cross-disciplinary debate and discussion as new life forms are emanating through science and medicine [13].

\section{Competing interests}

The authors declare that they have no competing interests. 


\section{References}

1 Patra SAA (2015) Effects of Genetic Engineering - The Ethical and Social Implications. Annals of Clinical and Laboratory Research.

2 Fischer A, Hacein-Bey S, Cavazzana-Calvo M (2002) Gene therapy of severe combined immunodeficiencies. Nat Rev Immunol 2: 615-621.

3 D'Halluin K, Ruiter R (2013) Directed genome engineering for genome optimization. Int J Dev Biol 57: 621-627.

4 Mercer DK, Scott KP, Bruce-Johnson WA, Glover LA, Flint HJ (1999) Fate of free DNA and transformation of the oral bacterium Streptococcus gordonii DL1 by plasmid DNA in human saliva. Appl Environ Microbiol 65: 6-10.

5 Jr FW (1996) Viral Genetics. In: Medical Microbiology. 4th Edition edn. University of Texas Medical Branch at Galveston.

6 Mepham TB (2000) The role of food ethics in food policy. The Proceedings of the Nutrition Society 59: 609-618.

7 Deuschle K, Fehr M, Hilpert M, Lager I, Lalonde S, et al. (2005) Genetically encoded sensors for metabolites. Cytometry A 64: 3-9.
8 Youm JW, Jeon JH, Kim H, Kim YH, Ko K, et al. (2008) Transgenic tomatoes expressing human beta-amyloid for use as a vaccine against Alzheimer's disease. Biotechnol lett 30: 1839-1845.

9 Naz RK (2009) Development of genetically engineered human sperm immunocontraceptives. J reprod immunol, 83: 145-150.

10 Smith JM (2003) Seeds of Deception: Exposing Industry and Government Lies About the Safety of the Genetically Engineered Foods You're Eating.

11 Powledge TM (2002) Will they throw the bath water out with the baby?: The US Congress is still debating whether to outlaw cloning humans. EMBO Reports 3: 209-211.

12 Sayler GS, Ripp S (2000) Field applications of genetically engineered microorganisms for bioremediation processes. Curr opin in biotechnol 11: 286-289.

13 Powledge TM (2002) Will they throw the bath water out with the baby? The US Congress is still debating whether to outlaw cloning humans. EMBO Rep 3: 209-211. 